\title{
When is a surgical multidisciplinary approach required in the management of head and neck non-melanoma skin cancer and in advanced head and neck pathologies involving skin?
}

\author{
Quando è indicato un approccio chirurgico multidisciplinare nel management \\ dei tumori primitivi cutanei non melanocitari della testa e del collo e dei tumori \\ localmente avanzati del distretto testa-collo con interessamento della cute?
}

\author{
Giovanni Almadori', Eugenio De Corso², Stefano Settimi², Giovanni Di Cintio², Dario Antonio Mele², Francesca Brigato², \\ Gaetano Paludetti², Marzia Salgarello ${ }^{3}$ \\ ${ }^{1}$ Cervico-Facial Oncological Surgery Unit, "A. Gemelli" Hospital Foundation IRCCS, Catholic University of the Sacred Heart, Rome, Italy; \\ 2 Otorhinolaryngology and Head-Neck Surgery Unit, "A. Gemelli" Hospital Foundation IRCCS, Catholic University of the Sacred Heart, Rome, \\ Italy; ${ }^{3}$ Plastic and Reconstructive Surgery Unit, "A. Gemelli" Hospital Foundation IRCCS, Catholic University of the Sacred Heart, Rome, Italy
}

\begin{abstract}
SUMMARY
Non-melanoma Skin cancer, including cutaneous squamous cell carcinoma and basal cell carcinoma, is the most common form of malignancy in the Caucasian population, and the skin of the head and neck is the site most involved. They should not be underestimated; in particular, high-risk lesions and advanced skin cancers require accurate diagnostic work up, aggressive surgical treatment and should be managed by the head and neck surgeon, the dermatologist and the plastic surgeon. Cutaneous head-neck malignancies are often overlooked or not routinely treated with a multidisciplinary surgical approach. Similarly, for primary head and neck cancers with involvement of surrounding skin, the involvement of the dermatologist and the plastic surgeon could better define an adequate diagnosis and treatment planning. The management of these patients presents both therapeutic and ethical problems, because the poor prognosis is burdened by facial disfigurement, open malodorous wounds and intractable pain. Therefore, in patients with advanced disease that is not candidate to radical surgery, palliative surgery with flap reconstruction could take place and could be proposed to improve quality of life.
\end{abstract}

KEY WORDS: non-melanoma skin cancer, head and neck cancer, multidisciplinary team, head and neck reconstruction, palliative surgery

\section{RIASSUNTO}

I tumori della pelle non melanocitari, che comprendono soprattutto il carcinoma squamocellulare e il carcinoma basocellulare, sono i tumori maligni più frequenti nella popolazione caucasica, e la cute della testa e del collo rappresenta la sede più coinvolta. Tali tumori non dovrebbero essere sottovalutati, in particolare le cosiddette lesioni ad alto rischio e $i$ tumori cutanei avanzati richiedono un iter diagnostico più accurato e un trattamento chirurgico più aggressivo, che dovrebbe essere gestito coinvolgendo il chirurgo testa-collo, il dermatologo e il chirurgo plastico. Le neoplasie primitive cutanee del distretto testa-collo sono spesso trascurate e non sono routinariamente discusse in seno a teams chirurgici multidisciplinari. Allo stesso modo, per i tumori primari della testa e del collo con infiltrazione cutanea, il coinvolgimento del dermatologo e del chirurgo plastico può più efficacemente definire la diagnosi e pianificare il trattamento. La gestione di questi pazienti pone problemi sia terapeutici che etici, perché la prognosi infausta è gravata da importanti inestetismi facciali, ferite aperte maleodoranti e dolore intrattabile. Pertanto, anche nei pazienti con malattia avanzata non suscettibile di chirurgia radicale, la chirurgia potrebbe ugualmente trovare spazio, ma con finalità palliativa, al fine di migliorare la qualità di vita.

PAROLE CHIAVE: tumori della cute non melanocitari, tumori testa-collo, trattamento multidisciplinare, ricostruzione del distretto testa-collo, chirurgia palliativa
Received: September 29, 2020

Accepted: January 14, 2021

\section{Correspondence}

Eugenio De Corso

Otorhinolaryngology, Head and Neck Surgery,

"A. Gemelli" Hospital Foundation IRCCS, Catholic University of the Sacred Heart

largo A. Gemelli 8, 00168 Rome, Italy

E-mail: eugenio.decorso@policlinicogemelli.it

Funding

None.

Conflict of interest

The Authors declare no conflict of interest.
How to cite this article: Almadori G, De Corso E, Settimi $\mathrm{S}$, et al. When is a surgical multidisciplinary approach required in the management of head and neck non-melanoma skin cancer and in advanced head and neck pathologies involving skin? Acta Otorhinolaryngol Ital 2021;41(SUPPL.1):S145-S157. https://doi. org/10.14639/0392-100X-suppl.1-41-2021-15

(C) Società Italiana di Otorinolaringoiatria e Chirurgia Cervico-Facciale

\section{(c) (i) $\$$}

This is an open access article distributed in accordance with the CC-BY-NC-ND (Creative Commons Attribution-NonCommercial-NoDerivatives 4.0 International) license. The article can be used by giving appropriate credit and mentioning the license, but only for non-commercial purposes and only in the original version. For further information: https:// creativecommons.org/licenses/by-nc-nd/4.0/deed.en 


\section{Introduction}

Non-melanoma Skin Cancer (NMSC) is the most common form of malignancy in the Caucasian population, and the skin of the head and neck is the site most involved. Basal cell carcinoma (BCC) and cutaneous squamous cell carcinoma (CSCC) make up the majority of these tumours ${ }^{1}$, while a less frequent histotype is the neuroendocrine tumor that arise from Merkel cells, an insidious carcinoma originating in most of cases on the facial skin. Early stages should not be undervalued because of their propensity to local invasion and heterogeneity; therefore, inadequate treatment can lead local recurrences and uncontrolled skin cancer requiring complex surgery, high patient morbidity and even death ${ }^{2}$. Finally, personalized treatment should be tailored taking into account the best oncological outcome and the best aesthetic and functional results.

The anatomic complexity of the head and neck district and the overlap between the operating fields of the ENT surgeon, the plastic surgeon and the dermatologist, lead to an even more complex surgical approach to NMSC; nevertheless, the histological heterogeneity of tumors involving the skin of the scalp, the face and the neck, often requires a surgical multidisciplinary approach to these lesions, with the aim of a balanced outcome in terms of oncological radicality and aesthetical result. Usually, the dermatologist is involved in the management of small primary skin tumors, due to his predominant role in the diagnosis of these lesions; however, a complete dermatologic evaluation of the skin in all districts is often required by other specialists in case of systemic and diffuse tumors, such as Merkel cell carcinoma. On the other hand, advanced primary NMSCs of the head and neck, with their infiltrative growth pattern, may involve subcutaneous tissue, muscle, bones, peripheral nerves, and lymph nodes, thus requiring an ENT surgical approach. Finally, primary head and neck cancers originating from the epithelial surface of the upper aerodigestive tract (UADT) and from other structures of the head and neck district, such as salivary glands and bone, may extend to surrounding structures and involve the skin of the face and the neck; in these advanced cases, the cooperation between the ENT surgeon and the plastic surgeon often represents the most convenient approach in order to perform a radical and functional resection of the tumours and a concurrent reconstruction with favorable aesthetic results ${ }^{3}$. The management of these patients is complex and challenging for all the specialists involved and it poses both therapeutic and ethical problems, due to the extended resection and the reduction in terms of quality of life after such a surgery. However, although the oncologic radicality should always be the primary aim of the surgeon, patients with very advanced head and neck tumours, originating or extending to the skin, may be considered not eligible for a radical surgery (due to vascular infiltration, distant metastasis or extension to the skull base), but they may benefit from a "palliative surgery", a concept introduced about fifty years ago ${ }^{4}$. Thanks to advances in reconstructive surgery, in particular the use of regional and free flaps, palliative resection and reconstruction is now a reasonable treatment option ${ }^{5}$.

A narrative review of the literature was performed to thoroughly investigate on both primary head and neck skin cancer and involvement of facial skin by head and neck tumours, in particular to highlight when surgical multidisciplinary approach is recommended.

\section{Primary skin cancers}

Non-melanoma skin cancers

Every year about 3.5 million of NMSC are treated all over the world and almost 75,000 new cases are diagnosed annually ${ }^{6}$. Skin cancer rates have been increasing since the ' 70 s, passing from an incidence rate of 8 per 100,000 to 31 per 100,000 nowadays, with an increase of about $290 \%{ }^{7}$. Risk factors for skin malignancy include cumulative sun exposure and/or sunburns, Fitzpatrick skin types I and II, ionizing radiation, acquired or inherited immunosuppression, genetic factors, presence of areas of chronic inflammation after burn or trauma. UVB radiations ( 290 to $320 \mathrm{~nm}$ ) may cause direct DNA damage and are involved in aetiology of NMSC. In particular, intense and intermittent sun exposure during first years of life represent a risk factor for BCC and cumulative UV radiation dose seems to be associated with $\mathrm{CSCC}^{8}$.

The Basal Cell Carcinoma (BCC) is an epithelial malignancy characterized by slow growth, that develops from epidermis basal layer. It has an age-adjusted incidence and prevalence of 226 and 343 per 100,000 persons per year, respectively; it presents locally destructive behaviour, but it rarely gives metastasis, occurring in approximately 0.003 percent to 0.1 percent of cases ${ }^{9}$. BCC is the most common skin malignancy all over the world, occurring in almost $80 \%$ of cases in head and neck region, with high prevalence on nose skin ${ }^{10}$. BCC is associated with intermittent recreational sun exposure, and genetic factors such as mutations in cell-cycle control genes (i.e. TP53, PTCH1, Sonic Hedgehog pathway) are common. Genetic syndromes like Gorlin syndrome and xeroderma pigmentosum also play a role in some BCCs ${ }^{11}$. Types of BCC are nodular (most common variant), superficial multifocal, sclerosing, infiltrative and morpheaform. About $20 \%$ of BCC show infiltrative growth pattern with high recurrence rate. Morpheaform BCC pre- 
sents as a yellow plaque, similar to a scar, with indistinct margins, that extends widely intradermally. Ulcus terebrans is another aggressive type of BCC that invades underlying structures such as large vessels, bones and meninges; it could be fatal due to haemorrhage or infection ${ }^{12}$.

Cutaneous Squamous Cell Carcinoma (CSCC) arises from keratinocytes with a locally destructive and metastatic potential. It affects 100/100,000 men and 50/100,000 women per year, representing the second most common skin cancer. Risk factors are similar to BCC, but specific factors are HPV infections, most commonly correlated to HPV 16 and 18 , but also types 31,33 , and 38 have been implicated ${ }^{13}$. The most common gene mutations are TP53, mutations in the RAS family of human oncogenes (HRAS, KRAS) and PTCH1. Deletions in CSCC involve several chromosomes, including 3p, 9p, 9q, 13q, 17p and 17q, with a higher degree of genomic instability compared with $\mathrm{BCC}$ and more frequent presence of aneuploid cells ${ }^{14}$. The develop of SCC follows the classic pattern of cancers from precursor lesions (mild, moderate, severe dysplasia) to tumour progression, and subsequent metastasis. Histologic grades range from well differentiated, that show keratinization and dermal invasion of round tumour margin, to poorly differentiated without keratinization and cellular organization, with blurred borders and projections into surrounding tissues ${ }^{15}$. The risk of developing lymph node metastasis in patients with CSCC is 3 to $5 \%$, but increases in high-risk patients with high rates (> 10 to $20 \%)^{16}$. Regional nodes can be divided into two groups: parotid (preauricular and parotid tail) and cervical nodes (levels I to V). The site of a CSCC is a determinant of the potential lymph node metastasis. For lesions in the lateral aspect of the head, metastases are commonly identified in parotid, level II and external jugular nodes. Parotid nodes represent the first echelon of lymphatic from the forehead, anterior scalp, temple, face and ear. Facial lesions tend to metastasize also to level I and II; while anterior lesions of the scalp, ear, temple, and forehead usually metastasize also to level II. Lesions posterior to the tragus usually metastasize to level V or to occipital nodes. Drainage to contralateral nodes occurs in $10 \%$ of patients, in particular in midline cancers ${ }^{17}$.

Bowen disease, also referred as squamous cell carcinoma in situ, appears as a well demarcated, erythematous plaque that slowly enlarges. Ulceration and induration are hallmarks of the transformation to SCC. Progression to invasive SCC occurs at 5\% per lesion per year. Treatment options include excision, electrodessication, and curettage ${ }^{18}$.

\section{Non-epithelial skin cancers}

Merkel cell carcinoma (MCC) (Fig. 1) is a neuroendocrine tumour that, on the basis of histomorphology, gene expression profiling and molecular analyses, has been hypothesized to originate from Merkel cell precursors (potentially derived from epidermal stem cells or hair follicle stem cells), pre-B cells, pro-B cells or dermal fibroblasts. Because normal Merkel cells are terminally differentiated and do not undergo cell division, they are unlikely to be the cell of origin for MCC. Merkel cells derives embryologically from neural crest cells and are receptor cells to somatosensory afferents for touch discrimination. MCC has an occurrence rate of 0.6/100,000 people per year. The skin face is the most common location at about $25 \%$. The risk factors are sun exposure, immunosuppression and polyomavirus (MCPyV) infection; this virus can be found integrated in the genome of more than $80 \%$ of tumours ${ }^{19}$. MCC carcinogenesis can be initiated by the clonal integration of the MCPyV genome or UV-mediated DNA damage caused by chronic exposure to sunlight, since UV exposure could also play a part in viral carcinogenesis by causing local immunosuppression. UV radiation induces the expression of inflammatory mediators and functional alterations in the antigen-presenting dendritic cells, which result in a cascade of events that modulate immune sensitivity. MCC clinically presents as a nodular lesion with rapid growth pattern, nontender, fleshcolored or blue-red colored and, due to the nonspecific presentation, clinical diagnosis of MCC is often delayed. Treatment consists of surgical excision with wide margins and particular attention to deep margin. Postoperative radiation is becoming accepted as the standard treatment. Before the advent of immunotherapy, no evidence supported adjuvant chemotherapy benefit ${ }^{20}$. However, over the last few years, the presence of PD-1 and PD-L1 has been demonstrated within tumour and immune cells. For the checkpoint inhibitors pembrolizumab and avelumab, responses of about $50 \%$ have been shown ${ }^{21}$.

Dermatofibrosarcoma Protuberans (DFSP) is a rare lowgrade soft tissue sarcoma; it is locally aggressive, with high rates of local recurrence but less than 5\% tend to metastasize. DFSP affects 0.8 to 4 cases per million annually and most commonly arises in the 3rd decade of life, but also pediatric cases occur. Only 14\% of DFSP involve head and neck. Patients with unresectable positive margins or metastatic disease may gain benefit from radiation or the tyrosine kinase inhibitors ${ }^{22}$.

Malignant tumors of the adnexa (Fig. 2) derive from the pilosebaceous unit and sweat glands, eccrine and apocrine. Among them, tumours that show a predilection toward head and neck district are sebaceous carcinoma, primary cutaneous mucinous carcinoma, microcystic adnexal carcinoma and malignant cylindroma. Risk factors include previous irradiation and immunosuppression. Neck nodal metastasis are reported in $8 \%$ of cases but are often under- 


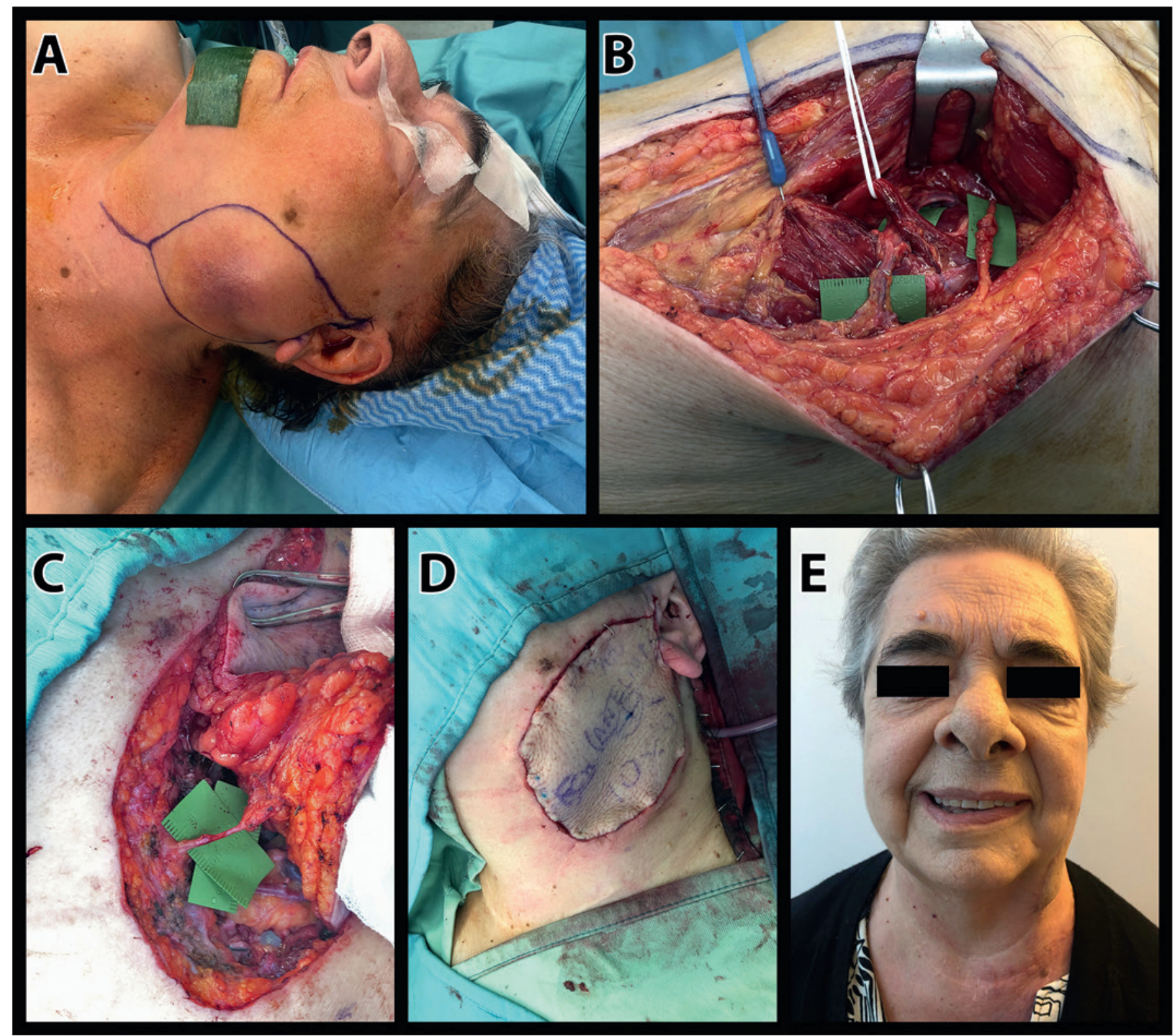

Figure 1. Eighty-three years old woman with parotid gland metastases of a cutaneous Merkel-cell carcinoma of the upper eyelid (treated 1 year before); the patient presented a clinical palsy of the inferior branches of facial nerve. (A) external appearance of the tumour; (B) harvesting of the ALT flap with preservation of the vascularized femoral-cutaneous sensory nerve for facial nerve reconstruction; dimensions: $9 \times 8 \mathrm{~cm}$; $(\mathbf{C})$ insetting of the flap and distal anastomosis of the vascularized femoral-cutaneous nerve to the marginalis mandibulae nerve; the proximal anastomosis was performed on the inferior branch of facial nerve; (D) final result after vascular anastomosis; (E) functional result with smile after 6 months.

evaluated; distant metastasis incidence is quite rare. Local recurrence rate is about $6 \%$ after surgical excision. Surgery is the gold-standard, RT can be useful as adjuvant treatment for positive margins or presence of perineural invasion ${ }^{23}$.

\section{Diagnosis of primary skin cancers}

Diagnosis of primary skin cancers is usually clinical, with subsequent histological confirmation. Following a thorough history and physical examination with palpation of draining lymph node basins, tissue biopsy (i.e., shave, punch, or excisional) remains the standard of care for diagnosing nonmelanoma skin cancers ${ }^{24}$. However, in case of the sampling error with punch and shave biopsies, in 11 to $19 \%$ of cases a more aggressive histologic subtype may be missed ${ }^{25,26}$. Patients commonly report a remote history of a previously resected cutaneous malignancy, which may explain new-on- 


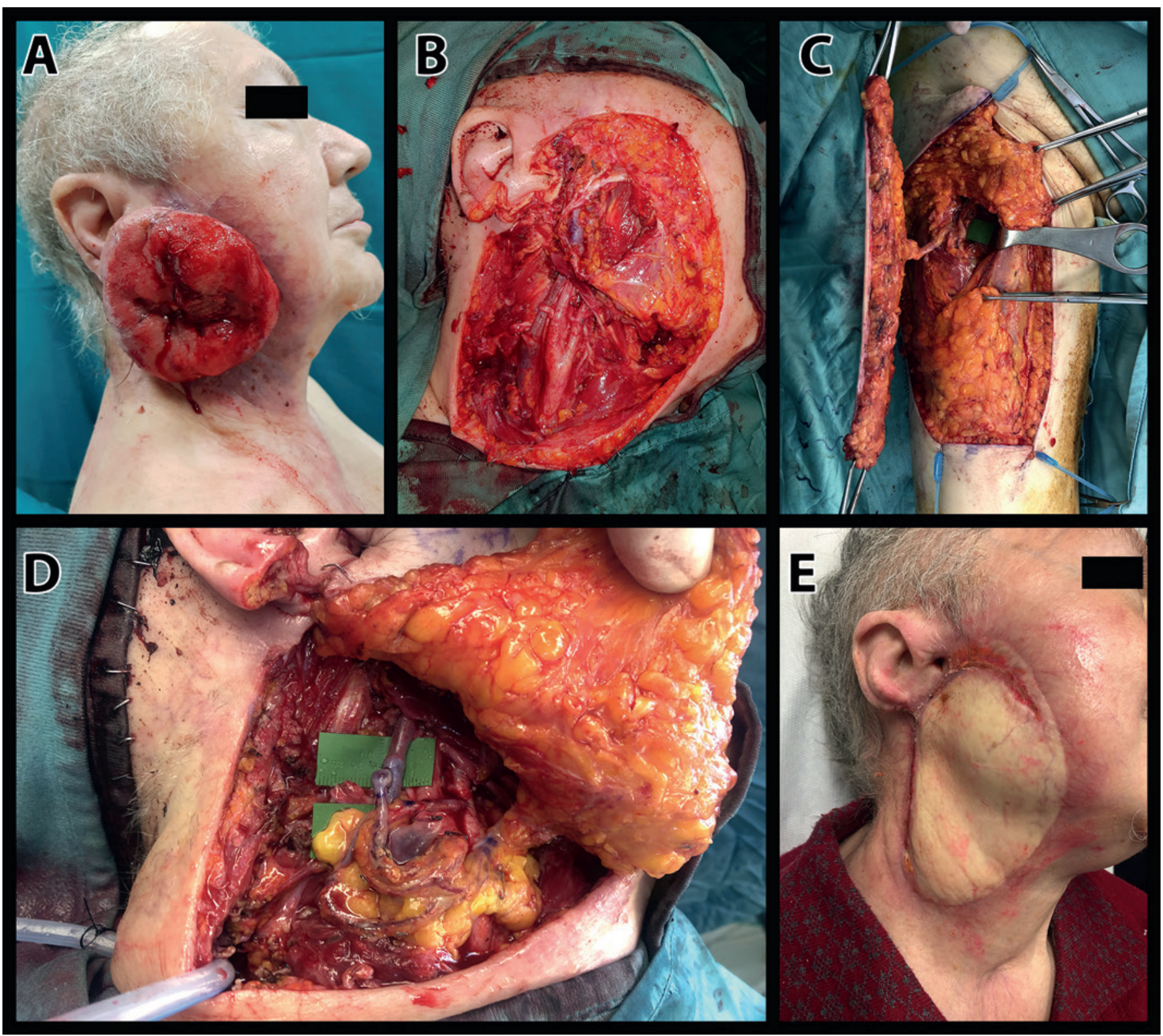

Figure 2. Seventy-nine years old woman with sebaceous carcinoma of the skin, extended to the external ear and parotid gland. (A) external appearance of the large tumour;(B) surgical resection of the tumour and total parotidectomy (with facial nerve preservation) extended to the lobule and the concha of the external ear; (C) ALT flap harvesting; dimensions: $13 \times 10 \mathrm{~cm}$; (D) insetting of the flap and anastomosis on the external carotid artery and internal jugular vein (double venous anastomosis); (E) Final result after 1 month.

set neck adenopathy, facial paresthesia, or a facial nerve paralysis. Complaints that suggest perineural invasion include facial weakness, hypesthesia, dysesthesia, and paresthesia. A recurrent lesion may present as a slow growing subcutaneous mass that invades the deep facial or neck musculature. A complete dermatologic examination is necessary for the patient with NMSC in order to find out eventual second primary tumours, especially in the suspect of a MCC, and dermoscopic examination of the lesions can be helpful in dif- ferential diagnosis ${ }^{27}$. MCC usually spreads to the regional lymph nodes; thus, sentinel lymph node biopsy (SLNB; that is removal and examination of the sentinel node) represents an important staging procedure and if the lymph nodes of the draining basin are clinically negative, it should be considered and planned at the same time as the wide local excision. The presence of occult nodal metastasis, in fact, is a strong prognostic factor and clinically occult nodal micrometastases are present in about $30 \%$ of patients ${ }^{21}$. 
The most widely adopted staging system for staging CSCC and BCC is the TNM Classification of Malignant Tumours, $8^{\text {th }}$ Edition (Tab. I). Moreover, basing on clinical and pathological features, both CSCC and BCC are classified in Low-Risk Lesions and High-Risk Lesions, according to the risk of local relapse and locoregional diffusion. High-Risk $\mathrm{BCC}$ and $\mathrm{CSCC}$ require more accurate diagnostic work up and more aggressive surgical treatment ${ }^{28}$. As showed in Table II and Table III, BCC and CSCC share most of the prognostic factors, such as: location, poorly defined borders, recurrent lesion, immunosuppressed patient, site of prior radiotherapy, perineural involvement, and aggressive histologic subtype. Squamous cell carcinomas have a few unique high-risk features, including chronic inflammatory process (e.g., Marjolin ulcer), rapidly growing tumours, neurologic symptoms, poor differentiation, depth greater than $6 \mathrm{~mm}$, lymphovascular invasion. For example, CSCC extending beyond subcutaneous fat (into deeper layers, such as the fascia, muscle, perichondrium, and periosteum) have an 11-fold higher risk of metastasis compared with more superficial tumours ${ }^{29}$; the presence of poor differentiation is associated with worse prognosis than well-differentiated CSCC, in particular local recurrence risk (7 vs 2\%) and metastatic risk (7 vs 3\%) ${ }^{30}$. Primary skin cancers involving sun-exposed areas of the head and neck do not usually require imaging for size assessment. In particular, low-risk $\mathrm{T} 1$ and $\mathrm{T} 2$ tumours rarely exhibit nodal metastasis and are staged primarily by clinical examination without additional imaging. However, the presence of adverse prognostic factors resulting from pathological examination, including those that increase $\mathrm{T}$ stage or those that increase risk classification, is often an indicator of aggressive behavior and may indicate additional imaging to assess occult nodal metastasis. These imaging modalities may include computed

Table I. TNM Staging of BCC and CSCC, AJCC $8^{\text {th }}$ Edition.

\begin{tabular}{|c|c|c|c|}
\hline \multicolumn{4}{|c|}{ T-staging } \\
\hline Tx & \multicolumn{3}{|l|}{ Primary tumor cannot be assessed } \\
\hline T0 & \multicolumn{3}{|l|}{ No evidence of primary tumor } \\
\hline Tis & \multicolumn{3}{|l|}{ Carcinoma in situ } \\
\hline T1 & \multicolumn{3}{|l|}{ Tumor smaller than or equal to $2 \mathrm{~cm}$ in greatest dimension } \\
\hline T2 & \multicolumn{3}{|c|}{ Tumor larger than $2 \mathrm{~cm}$, but smaller than or equal to $4 \mathrm{~cm}$ in greatest dimension } \\
\hline T3 & \multicolumn{3}{|c|}{ Tumor larger than $4 \mathrm{~cm}$ in maximum dimension or minor bone erosion or perineural invasion or deep invasion } \\
\hline T4a & \multicolumn{3}{|c|}{ Tumor with gross cortical bone/marrow invasion } \\
\hline T4b & \multicolumn{3}{|l|}{ Tumor with skull base invasion and/or skull base foramen involvement } \\
\hline \multicolumn{2}{|r|}{ N-staging BCC } & \multicolumn{2}{|r|}{ N-staging CSCC } \\
\hline NX & Regional lymph nodes cannot be assessed & NX & Regional lymph nodes cannot be assessed \\
\hline NO & No regional lymph node metastasis & NO & No regional lymph node metastasis \\
\hline N1 & $\begin{array}{l}\text { Metastasis in a single ipsilateral lymph node, } 3 \mathrm{~cm} \text { or smaller in } \\
\text { greatest dimension and ENE (-) }\end{array}$ & N1 & $\begin{array}{l}\text { Metastasis in a single ipsilateral lymph node, } 3 \mathrm{~cm} \text { or smaller in } \\
\text { greatest dimension and ENE (-) }\end{array}$ \\
\hline $\mathrm{N} 2 \mathrm{a}$ & $\begin{array}{l}\text { Metastasis in a single ipsilateral node larger than } 3 \mathrm{~cm} \text { but not larger } \\
\text { than } 6 \mathrm{~cm} \text { in greatest dimension and ENE (-) }\end{array}$ & N2a & $\begin{array}{l}\text { Metastasis in a single ipsilateral node } 3 \mathrm{~cm} \text { or smaller in greatest } \\
\text { dimension and ENE (+) or Metastasis in a single ipsilateral node } \\
\text { larger than } 3 \mathrm{~cm} \text { but not larger than } 6 \mathrm{~cm} \text { in greatest dimension and } \\
\text { ENE (-) }\end{array}$ \\
\hline $\mathrm{N} 2 \mathrm{~b}$ & $\begin{array}{l}\text { Metastasis in multiple ipsilateral nodes, none larger than } 6 \mathrm{~cm} \text { in } \\
\text { greatest dimension and ENE (-) }\end{array}$ & $\mathrm{N} 2 \mathrm{~b}$ & $\begin{array}{l}\text { Metastasis in multiple ipsilateral nodes, none larger than } 6 \mathrm{~cm} \text { in } \\
\text { greatest dimension and ENE (-) }\end{array}$ \\
\hline N2C & $\begin{array}{l}\text { Metastasis in bilateral or contralateral nodes, none larger than } 6 \mathrm{~cm} \\
\text { in greatest dimension and ENE (-) }\end{array}$ & $\mathrm{N} 2 \mathrm{C}$ & $\begin{array}{l}\text { Metastasis in bilateral or contralateral nodes, none larger than } 6 \mathrm{~cm} \\
\text { in greatest dimension and ENE (-) }\end{array}$ \\
\hline N3a & $\begin{array}{l}\text { Metastasis in a lymph node larger } 6 \mathrm{~cm} \text { in greatest dimension and } \\
\text { ENE }(-)\end{array}$ & N3a & $\begin{array}{l}\text { Metastasis in a lymph node larger } 6 \mathrm{~cm} \text { in greatest dimension and } \\
\text { ENE (-) }\end{array}$ \\
\hline N3b & Metastasis in any node(s) and ENE (+) & N3b & $\begin{array}{l}\text { Metastasis in a single ipsilateral node larger than } 3 \mathrm{~cm} \text { in greatest } \\
\text { dimension and ENE }(+) \text {; or multiple ipsilateral, contralateral, or } \\
\text { bilateral nodes any with ENE }(+) \text {; or a single contralateral node of any } \\
\text { size and ENE }(+)\end{array}$ \\
\hline \multicolumn{4}{|c|}{ M-staging } \\
\hline M0 & \multicolumn{3}{|l|}{ No distant metastasis } \\
\hline M1 & \multicolumn{3}{|l|}{ Distant metastasis } \\
\hline
\end{tabular}


Table II. BCC: prognostic factors for local recurrence or metastases.

\begin{tabular}{lcc} 
& Low-risk & High-risk \\
Clinical features & & Area $L \geq 20 \mathrm{~mm}$ \\
Location/size & Area $L<20 \mathrm{~mm} \geq 10 \mathrm{~mm}$ \\
& Area $\mathrm{M}<10 \mathrm{~mm}$ & Area $\mathrm{H}$ \\
Borders & Well defined & Poorly defined \\
Primary vs recurrent & Primary & Recurrent \\
Immunosuppression & Negative & Positive \\
Site of Prior RT & Negative & Positive \\
Pathological features & & Aggressive growth patterns \\
Subtype & Nodular, superficial & Positive \\
Perineural involvement & Negative & \\
\hline $\begin{array}{l}\text { Area H: "mask areas" of face (central face, eyelids, eyebrows, periorbital, nose, lips [cutaneous and vermilion], chin, mandible, preauricular and postauricular skin/sulci, temple, and } \\
\text { ear), genitalia, hands, and feet }\end{array}$ &
\end{tabular}

Table III. CSCC: prognostic factors for local recurrence or metastases.

\begin{tabular}{|c|c|c|}
\hline & Low-risk & High-risk \\
\hline \multicolumn{3}{|l|}{ Clinical features } \\
\hline Location/size & $\begin{array}{l}\text { Area } \mathrm{L}<20 \mathrm{~mm} \\
\text { Area } \mathrm{M}<10 \mathrm{~mm}\end{array}$ & $\begin{array}{c}\text { Area } L \geq 20 \mathrm{~mm} \\
\text { Area } \mathrm{M} \geq 10 \mathrm{~mm} \\
\text { Area } \mathrm{H}\end{array}$ \\
\hline Borders & Well defined & Poorly defined \\
\hline Primary vs recurrent & Primary & Recurrent \\
\hline Site of Prior RT or chronic inflammatory process & Negative & Positive \\
\hline Rapidly growing tumours & Negative & Positive \\
\hline Neurologic symptoms & Negative & Positive \\
\hline \multicolumn{3}{|l|}{ Pathological features } \\
\hline Degree of differentiation & Well or moderately differentiated & Poorly differentiated \\
\hline Perineural, lymphatic, or vascular involvement & Negative & Positive \\
\hline
\end{tabular}

tomography (CT) of the neck and/or magnetic resonance (MR) imaging with contrast enhancement. Stage III-IV cancers routinely undergo imaging prior to therapy, including a neck CT and/or MR imaging with contrast enhancement, as well as other modalities, such as a positron emission tomography (PET)-CT scan. CT is generally preferred over MRI for evaluating the primary tumour, the status of the lymph nodes, and the presence of bony invasion. MRI is better for the detection of perineural spread, dural inva- sion, and orbital disease. Patients with bulky lymph node metastasis should also be evaluated for distant metastasis with a CT scan of the chest ${ }^{31,32}$.

\section{Management of primary skin cancers}

Low-risk NMSC and small MCC could be managed by a single specialist (usually plastic surgeon or dermatologist), without multidiciplinary surgical approach. Surgical excision is the gold standard and margin assessment is manda- 
tory. In this way, 5-years disease-free survival is $95-98 \%$ for BCC and $92 \%$ for CSCC ${ }^{33,34}$. Management of high-risk NMSC and larger MCC is more complex. Surely, the treatment of choice is surgical removal, whether by conventional surgery or Mohs micrographic surgery. Recommended margins range from 4 to $6 \mathrm{~mm}$ for low-risk BCC and CSCC to 10 to $15 \mathrm{~mm}$ for high-risk lesions ${ }^{35}$. These wider margins are impractical for all regions of the head and neck, but only for those with such substantial tissue laxity as to allow closure of resultant large defects. Therefore, very extensive skin lesions, including certain highly aggressive tumours, such as those invading bone, major nerve branches, or with involvement of the parotid gland, are typically best approached with a multidisciplinary surgical team, involving the head and neck surgeon ${ }^{36,37}$. Lesions with nodal spread at diagnosis should be multidisciplinary treated as well. Nevertheless, cutaneous head-neck malignancies are often overlooked or not routinely discussed in a multidisciplinary surgical approach involving both the head and neck surgeon and the dermatologist and the plastic surgeon ${ }^{38}$.

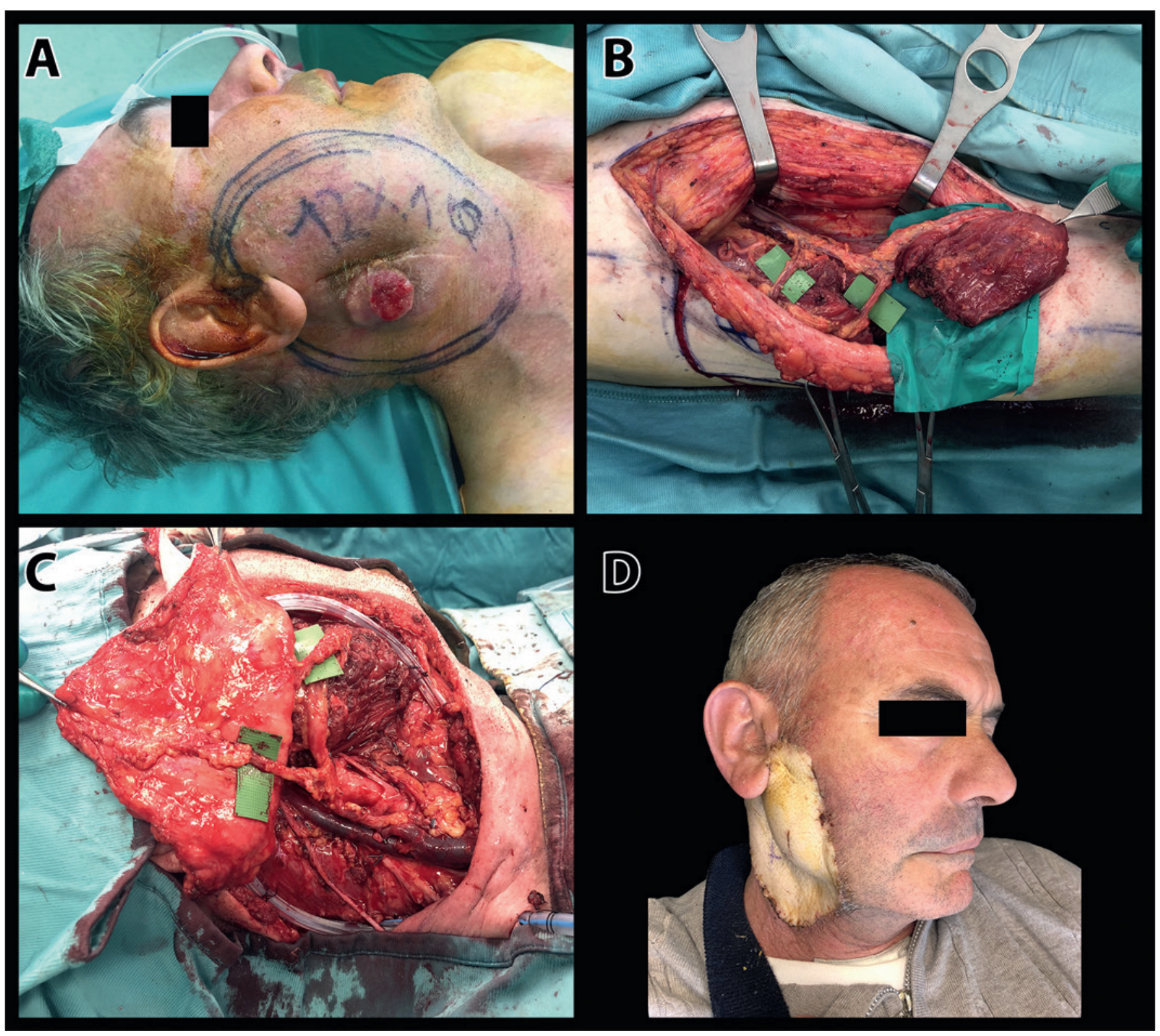

Figure 3. Fifty-four years old man with adenocarcinoma of the parotid gland extended to the skin of the parotid region. (A) external appearance of the tumour; (B) harvesting of the double pedicled chimeric ALT flap with a skin paddle and vastus lateralis paddle; dimensions: $12 \times 12 \mathrm{~cm}$; (C) insetting of the chimeric flap and vascular anastomosis; (D) final result after 1 month. 
Surgical management of all skin malignancies is dictated by the location and extent of the tumour. Small lesions of the face and neck can be excised elliptically in the plane of skin tension with excellent aesthetic results and surgical defects resulting from resection can be closed primarily after wide undermining. However, skin grafts are best suited to the part of the face with minimal facial motion, such as the tip or lateral aspect of the bridge of the nose, the temple or the parotid region where facial movement is minimal with excellent cosmetic results (Fig. 3). Local flaps are preferred to repair larger surgical defects or those requiring full-thickness reconstruction, because they provide the best functional and aesthetic outcome. Primary closure of the donor site defect usually can be accomplished with ease with proper planning of local skin flaps. The blood supply of facial skin and soft tissues is extremely rich because the terminal branches of the external carotid artery provide a major source of blood to the facial skin, which allows use of axial flaps. In addition, an extensive subdermal anastomotic network facilitates the use of random flaps. Examples of axial skin flaps are nasolabial, glabellar, Mustardé cheek, and temporal forehead. Examples of random flaps are cervical, rhomboid, and bilobed. If local flaps are not suitable, consideration should be given to regional or free flaps for appropriate repair of large surgical defects (Figs. 4,5). Moreover, we have to highlight the role of neck dissection in the management of skin cancer. In case of $\mathrm{cN}+$, neck dissection is mandatory; in case of $\mathrm{cNO}$, a recent manuscript stated that elective neck dissection should be performed in case of T3-T4 disease, regardless of other risk factors ${ }^{39}$.

\section{Head and neck cancers with skin involvement}

Head and neck squamous cell carcinomas (HNSCC) represent a group of aggressive tumors, genetically complexed and difficult to treat. Males are affected significantly more than females, with a ratio ranging from 2:1 to 4:1, between 50 and 70 years old ${ }^{40}$. Exposition to carcinogens, e.g. tobacco smoke and alcohol abuse, and human papilloma virus (HPV) infection are considered the most important etiological factors ${ }^{41}$. Approximately 30 to $40 \%$ of patients with HNSCC present with stage I or II (early stage disease). Five-year overall survival in patients with stage I or II disease is typically from 70 to 90 percent. Loco-regionally advanced (stage III-IV) HNSCC is associated with a high risk of both local recurrences and distant metastases. Combined modality approaches (surgery, RT, and/or chemotherapy) are generally required to optimize the chances for longterm disease control ${ }^{42,43}$. Skin involvement by non-cutaneous head and neck cancer is an infrequent finding, with a reported incidence of $9-11 \%{ }^{44}$. It is usually associated with locally advanced diseases, either primary head and neck tumours and recurrent ones. Therefore, skin invasion always indicates a T4 tumour, regardless of tumour site (major salivary glands, oral cavity, paranasal sinuses) and it is a sign of poor outcome. In fact, patients with direct skin invasion have a 7-months median survival. According to the same authors, involvement of facial skin is prognostically better for duration of survival than involvement of neck skin ${ }^{45}$.

\section{Diagnosis, staging and prognostic factors}

Diagnosis of head and neck tumours involving the skin, is initially clinical based on detailed history and accurate physical examination. If a primary tumour is identified, its site of origin, visual characteristics, palpatory findings, and physical signs of local extension and invasion of adjacent structures should be noted, and biopsy should be performed. Imaging plays an integral role in the evaluation of head and neck tumours. Imaging can help define the extent of the primary tumour as well as the presence, volume, and location of regional and distant metastases. In addition, imaging is helpful in detecting synchronous or metachronous primary tumours that may not be evident clinically. CT and MRI can complement each other to enhance the anatomic definition of selected tumours. PET/TC is particularly helpful in evaluating patients with advanced head and neck cancers for distant metastases and post-therapy recurrence ${ }^{46}$. When a surgical reconstruction with locoregional or microvascular free flap is required, in case of large resection, an ultrasound perforator assessment is needed by a radiologist experienced in the evaluation and study of perforator vessels. Radiologist using Doppler technique performs an analysis of best perforator, selecting the vessel with the largest caliber, and marking on the skin its fascial emergency site and subcutaneous direction, in order to evaluate the orientation of cutaneous island flap, creating a preoperative mapping in order to optimize the reconstructive procedure ${ }^{47-49}$.

Management of head and neck cancer with skin involvement Surgical management of head and neck malignancies with skin involvement poses several problems about the management of these patients because the poor prognosis is burdened by facial disfigurement, open malodorous wounds, and intractable pain. Chemoradiation is often considered the standard of care for patients with inoperable disease. However, it does not adequately address the abovementioned problems related to skin involvement, whereas extensive skin involvement is often amenable to surgery. Moreover, open wounds treated with chemoradiation will often enlarge and become more problematic. Yamazaki et 


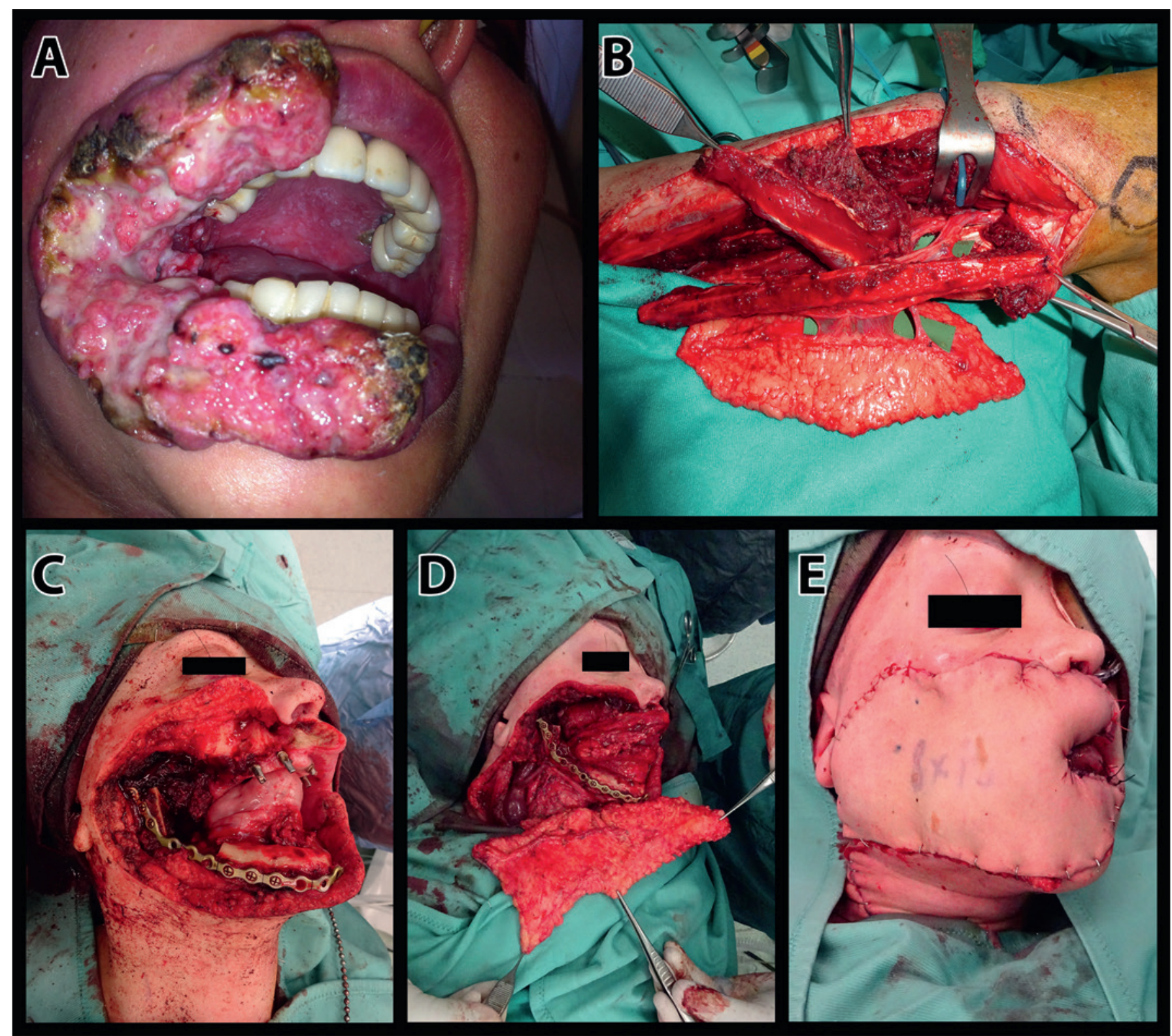

Figure 4. Young thirty-five years old woman with squamous cancer of the upper lip and buccal mucosa extended to the mandible and the skin of cheek. (A) external appearance of the large tumour; (B) harvesting of the osteocutaneous fibula flap; dimensions: $20 \times 8 \mathrm{~cm}$; (C) result after the tumour resection; the mandible titanium plate was applied before the resection in order to guide the osteotomies; (D) mandible reconstruction with the fibula flap and face resurfacing with a large DIEP flap; dimensions: $28 \times 10 \mathrm{~cm}$; (E) immediate final result.

al. aimed to elucidate the influence of skin invasion in patients with recurrent head and neck cancer treated with reirradiation using stereotactic radiotherapy. They described that the skin invasion positive group showed a lower response rate, a lower local control and a lower progression free survival than the skin invasion negative group ${ }^{50}$. In this scenario, thanks to reconstructive advances by use of microvascular free flaps, perforator or not, single or multiple, salvage surgery with curative intent is an effective option offering good oncological outcomes (in terms of overall survival, relapse and metastasis free survival and salvageability) and functional results. At this purpose, a close cooperation between otolaryngologist and plastic surgeon should be encouraged. In patients with persistent or recurrent disease that is not amenable to radical surgery, palliative surgery with reconstruction with regional or free flaps could take place and could be proposed to improve quality of life and quality of death. In a pioneering case 


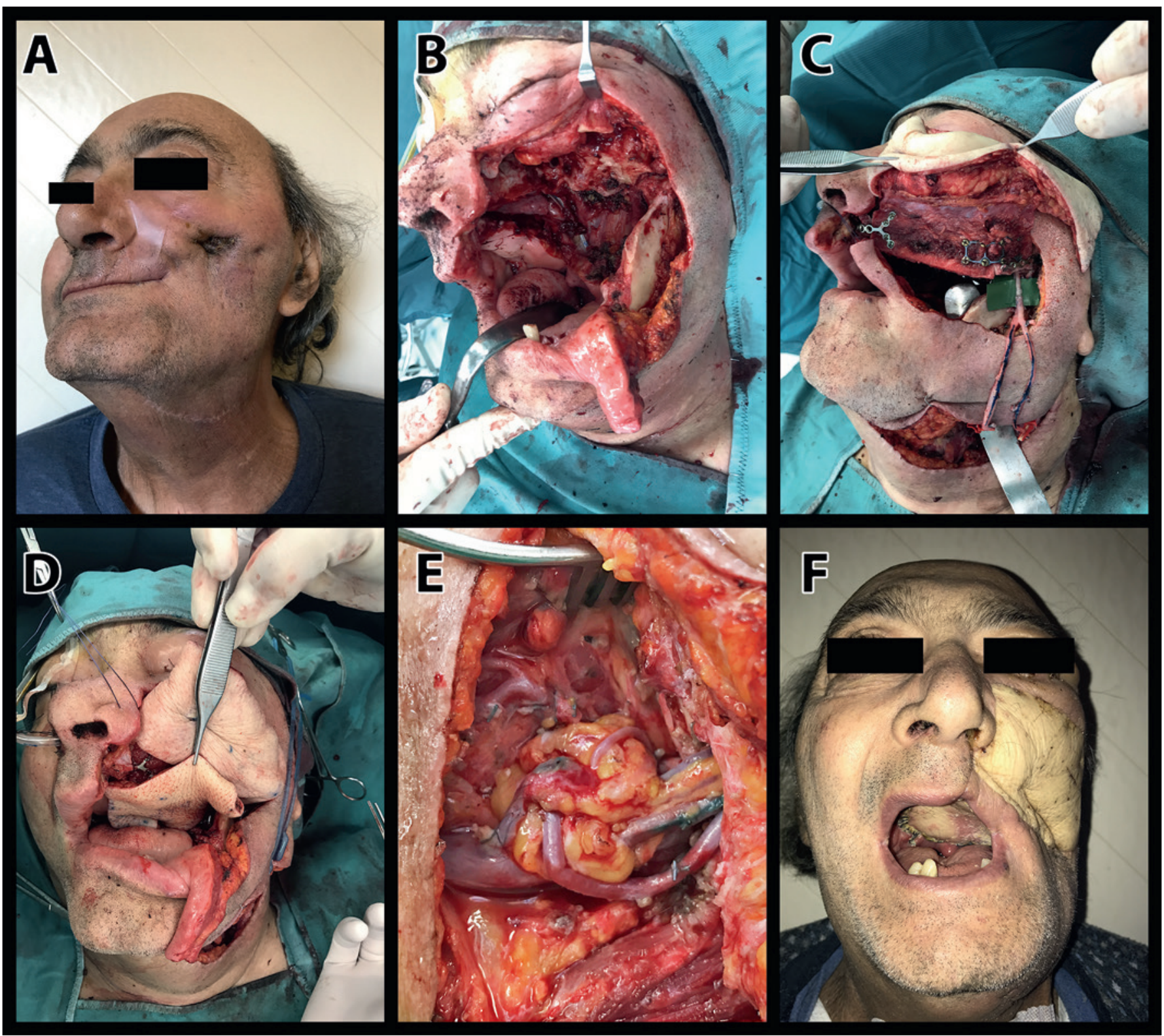

Figure 5. Sixty-four years old man with relapse of oral cavity cancer extended to the left maxillary sinus and the zygomatic skin. (A) external appearance of the tumour; (B) surgical result after extended total left maxillectomy; (C) insetting of the osteocutaneous fibula flap; dimensions: $17 \times 7 \mathrm{~cm}$; cutaneous paddle was used for the reconstruction of the oral cavity; (D) a second ALT flap was used to resurface the zygomatic region; (E) detail on the anastomosis of both the pedicles on the external carotid artery and jugular vein, with fat as stabilization; (F) final result after 1 month.

series, reported in 1993, in which 13 patients underwent palliative resection, there was an increased survival of 20 months beyond the median survival of the other patients. Thanks to the common use of microvascular free flaps in head and neck surgery, the prognosis of these patients has improved, as well. Jang et al. reported a median survival of 9.5 months (range: $1-30$ months) ${ }^{51}$. Stravianos et al. reviewed a case series of 31 patients: all patients underwent surgical resection with free flap reconstruction, the most common being the radial forearm $(78 \%)$. With this form of management, the authors reached a mean survival of 23 months, and six patients were still alive at follow up of 4.5 years ${ }^{52}$. Furthermore, this approach does not obviate the opportunity to undergo further chemoradiation.

\section{Conclusions}

Multidisciplinary surgical approach in the management of 
Table IV. Recommendations.

\begin{tabular}{lc} 
Indication & $\begin{array}{c}\text { Surgical multidisciplinary } \\
\text { approach }\end{array}$ \\
\hline Low-risk NMSC & $\begin{array}{c}\text { Optional } \\
\text { Recurrent NMSC } \\
\text { Recommended }\end{array}$ \\
$\begin{array}{l}\text { Nodal metastasis at diagnosis } \\
\text { Head and neck cancer with skin } \\
\text { involvement }\end{array}$ & $\begin{array}{c}\text { Strongly recommended } \\
\text { Strongly recommended }\end{array}$ \\
\hline
\end{tabular}

head and neck carcinomas involving the skin and high-risk primary skin cancer of head and neck district, is strongly recommended. Low-risk NMSCs and small MCC are routinely treated in some regions by community practitioners and dermatologists; however, national cancer networks should establish an integrated approach involving both the head and neck surgeon and the plastic surgeon to care for patients with certain high-risk CSCC and BCC and large MCC (Tab. IV). Cooperation between otolaryngologist and plastic surgeon is extremely helpful in order to better plan surgical treatment, including safe oncological excision and careful and accurate reconstruction, with a good aesthetic result.

\section{References}

1 Linares MA, Zakaria A, Nizran P. Skin cancer. Prim Care 2015;42:645659. https://doi.org/10.1016/j.pop.2015.07.006

2 Brandt MG, Moore CC. Nonmelanoma skin cancer. Facial Plast Surg Clin North Am 2019;27:1-13. https://doi.org/10.1016/j. fsc.2018.08.001

3 Matthiesen C, Thompson JS, Forest C, et al. The role of radiotherapy for T4 non-melanoma skin carcinoma. J Med Imaging Radiat Oncol 2011;55:407-416. https://doi.org/10.1111/j.1754-9485.2011.02277.x

4 ConleyJJ.Palliativesurgeryin theheadandneck.AnnOtolRhinolLaryngol 1962;71:585-590. https://doi.org/10.1177/000348946207100302

5 Egeler SA, Huang A, Johnson AR, et al. Regional incidence of and reconstructive management patterns in melanoma and nonmelanoma skin cancer of the head and neck: a 3-year analysis in the inpatient setting. J Plast Reconstr Aesthet Surg 2020;73:507-515. https://doi. org/10.1016/j.bjps.2019.10.017

6 Stang A, Khil L, Kajüter H, et al. Incidence and mortality for cutaneous squamous cell carcinoma: comparison across three continents. J Eur Acad Dermatol Venereol 2019;33:6-10. https://doi.org/10.1111/ jdv. 15967

7 Wehner MR, Shive ML, Chren MM, et al. Indoor tanning and nonmelanoma skin cancer: systematic review and meta-analysis. BMJ 2012;345:e5909. https://doi.org/10.1136/bmj.e5909

8 Zhang M, Qureshi AA, Geller AC, et al. Use of tanning beds and incidence of skin cancer. J Clin Oncol 2012;30:1588-1593. https://doi. org/10.1200/JCO.2011.39.3652

9 Marzuka AG, Book SE. Basal cell carcinoma: pathogenesis, epidemiology, clinical features, diagnosis, histopathology, and management. Yale J Biol Med 2015;88:167-179.
10 Lee KJ, Soyer HP. Cutaneous keratinocyte cancers of the head and neck: epidemiology, risk factors and clinical, dermoscopic and reflectance confocal microscopic features. Oral Oncol 2019;98:109-117. https://10.1016/j.oraloncology.2019.09.019

11 Ouyang YH. Skin cancer of the head and neck. Semin Plast Surg 2010;24:117-126. https://doi.org/10.1055/s-0030-1255329

12 Karagas MR, Stukel TA, Greenberg ER, et al. Risk of subsequent basal cell carcinoma and squamous cell carcinoma of the skin among patients with prior skin cancer. Skin Cancer Prevention Study Group. JAMA 1992;267:3305-3310.

13 Jemal A, Simard EP, Dorell C, et al. Annual Report to the Nation on the Status of Cancer, 1975-2009, featuring the burden and trends in human papillomavirus(HPV)-associated cancers and HPV vaccination coverage levels. J Natl Cancer Inst 2013;105:175-201. https:// doi.org/10.1093/jnci/djs491

14 Ashton KJ, Weinstein SR, Maguire DJ. Chromosomal aberrations in squamous cell carcinoma and solar keratoses revealed by comparative genomic hybridization. Arch Dermatol 2003;139:876-882. https:// doi.org/10.1001/archdem.139.7.876

15 McGuire JF, Ge NN, Dyson S. Nonmelanoma skin cancer of the head and neck I: histopathology and clinical behavior. Am J Otolaryngol 2009;30:121-133. https://doi.org/10.1016/j.amjoto.2008.03.002

16 Veness MJ, Palme CE, Morgan GJ. High-risk cutaneous squamous cell carcinoma of the head and neck: results from 266 treated patients with metastatic lymph node disease. Cancer 2006;106:2389-2396. https://doi.org/10.1002/cncr.21898

17 Ebrahimi A, Moncrieff MD, Clark JR, et al. Predicting the pattern of regional metastases from cutaneous squamous cell carcinoma of the head and neck based on location of the primary. Head Neck 2010;32:1288-1294. https://doi.org/10.1002/hed.21332

18 Kao GF. Carcinoma arising in Bowen's disease. Arch Dermatol 1986;122:1124-1126.

19 Rodig SJ, Cheng J, Wardzala J, et al. Improved detection suggests all Merkel cell carcinomas harbor Merkel polyomavirus. J Clin Invest 2012;122:4645-4653. https://doi.org/10.1172/JCI64116

20 Kaae J, Hansen AV, Biggar RJ, et al. Merkel cell carcinoma: incidence, mortality, and risk of other cancers. J Natl Cancer Inst 2010;102:793801. https://doi.org/10.1093/jnci/djq120

21 Becker JC, Stang A, DeCaprio JA, et al. Merkel cell carcinoma. Nat Rev Dis Primers 2017;3:17077. https://doi.org/10.1038/nrdp.2017.77

22 Sjöblom T, Shimizu A, O'Brien KP, et al. Growth inhibition of dermatofibrosarcoma protuberans tumors by the platelet-derived growth factor receptor antagonist STI571 through induction of apoptosis. Cancer Res 2001;61:5778-5783.

23 Oyasiji T, Tan W, Kane J $3^{\text {rd }}$, et al. Malignant adnexal tumors of the skin: a single institution experience. World J Surg Oncol 2018;16:99. https://doi.org/10.1186/s12957-018-1401-y

24 Mendez BM, Thornton JF. Current basal and squamous cell skin cancer management. Plast Reconstr Surg 2018;142:e373-e387. https:// doi.org/10.1097/PRS.0000000000004696

25 Wolberink EA, Pasch MC, Zeiler M, et al. High discordance between punch biopsy and excision in establishing basal cell carcinoma subtype: analysis of 500 cases. J Eur Acad Dermatol Venereol 2013;27:985-989. https://doi.org/10.1111/j.1468-3083.2012.04628.x

26 Roozeboom MH, Mosterd K, Winnepenninckx VJ, et al. Agreement between histological subtype on punch biopsy and surgical excision in primary basal cell carcinoma. J Eur Acad Dermatol Venereol 2013;27:894-898. https://doi.org/10.1111/j.1468-3083.2012.04608.x

27 Cassarino DS, Derienzo DP, Barr RJ. Cutaneous squamous cell carcinoma: a comprehensive clinicopathologic classification. Part one. J Cutan Pathol 2006;33:191-206. https://doi. org/10.1111/j.0303-6987.2006.00516_1.x 
28 Kyrgidis A, Tzellos TG, Kechagias N, et al. Cutaneous squamous cell carcinoma (SCC) of the head and neck: risk factors of overall and recurrence-free survival. Eur J Cancer 2010;46:1563-1572. https:// doi.org/10.1016/j.ejca.2010.02.046

29 Thompson AK, Kelley BF, Prokop LJ, et al. Risk factors for cutaneous squamous cell carcinoma recurrence, metastasis, and disease-specific death: a systematic review and meta-analysis. JAMA Dermatol 2016;152:419-428. https://doi.org/10.1001/jamadermatol.2015.4994

30 Brantsch KD, Meisner C, Schönfisch B, et al. Analysis of risk factors determining prognosis of cutaneous squamous-cell carcinoma: a prospective study. Lancet Oncol 2008;9:713-720. https://doi. org/10.1016/S1470-2045(08)70178-5

31 MacFarlane D, Shah K, Wysong A, et al. The role of imaging in the management of patients with nonmelanoma skin cancer: diagnostic modalities and applications. J Am Acad Dermatol 2017;76:579-588. https://doi.org/10.1016/j.jaad.2015.10.010

32 Mendenhall WM, Amdur RJ, Hinerman RW, et al. Skin cancer of the head and neck with perineural invasion. Am J Clin Oncol 2007;30:9396. https://doi.org/10.1097/01.coc.0000251224.16075.60

33 Walker P, Hill D. Surgical treatment of basal cell carcinomas using standard postoperative histological assessment. Australas J Dermatol 2006;47:1-12. https://doi.org/10.1111/j.1440-0960.2006.00216.x

34 Lansbury L, Bath-Hextall F, Perkins W, et al. Interventions for nonmetastatic squamous cell carcinoma of the skin: systematic review and pooled analysis of observational studies. BMJ 2013;347:f6153. https://doi.org/10.1136/bmj.f6153

35 Parikh SA, Patel VA, Ratner D. Advances in the management of cutaneous squamous cell carcinoma. F1000Prime Rep 2014;6:70. https:// doi.org/10.12703/P6-70

36 Fu T, Aasi SZ, Hollmig ST. Management of high-risk squamous cell carcinoma of the skin. Curr Treat Options Oncol 2016;17:34. https:// doi.org/10.1007/s11864-016-0408-2

37 Franzen A, Buchali A, Lieder A. The rising incidence of parotid metastases: our experience from four decades of parotid gland surgery. Acta Otorhinolaryngol Ital 2017;37:264-269. https://doi. org/10.14639/0392-100X-1095

38 Newlands C, Currie R, Memon A, et al. Non-melanoma skin cancer: United Kingdom National Multidisciplinary Guidelines. J Laryngol Otol 2016;130:S125-S132. https://doi.org/10.1017/ S0022215116000554

39 Xiao Y, Yuan S, Liu F, et al. Comparison between wait-and-see policy and elective neck dissection in clinically N0 cutaneous squamous cell carcinoma of head and neck. Medicine (Baltimore) 2018;97:e10782. https://doi.org/10.1097/MD.0000000000010782

40 Bray F, Ren JS, Masuyer E, et al. Global estimates of cancer prevalence for 27 sites in the adult population in 2008. Int J Cancer 2013;132:1133-1145. https://doi.org/10.1002/ijc.27711

41 Wyss A, Hashibe M, Chuang SC, et al. Cigarette, cigar, and pipe smoking and the risk of head and neck cancers: pooled analysis in the
International Head and Neck Cancer Epidemiology Consortium. Am J Epidemiol 2013;178:679-690. https://doi.org/10.1093/aje/kwt029

42 Pignon JP, le Maître A, Maillard E, et al. MACH-NC Collaborative Group. Meta-analysis of chemotherapy in head and neck cancer (MACH-NC): an update on 93 randomised trials and 17,346 patients. Radiother Oncol 2009;92:4-14. https://doi.org/10.1016/j. radonc.2009.04.014

43 Furness S, Glenny AM, Worthington HV, et al. Interventions for the treatment of oral cavity and oropharyngeal cancer: chemotherapy. Cochrane Database Syst Rev 2011:CD006386. https://doi. org/10.1002/14651858.CD006386.pub3

44 Lookingbill DP, Spangler N, Helm KF. Cutaneous metastases in patients with metastatic carcinoma: a retrospective study of 4020 patients. J Am Acad Dermatol 1993;29:228-236. https://doi. org/10.1016/0190-9622(93)70173-q

45 Cole RD, McGuirt WF. Prognostic significance of skin involvement from mucosal tumors of the head and neck. Arch Otolaryngol Head Neck Surg 1995;121:1246-1248. https://doi.org/10.1001/ archotol.1995.01890110024004

46 Jung AR, Roh JL, Kim JS, et al. Post-treatment 18F-FDG PET/ $\mathrm{CT}$ for predicting survival and recurrence in patients with advanced-stage head and neck cancer undergoing curative surgery. Oral Oncol 2020;107:104750. https://doi.org/10.1016/j. oraloncology.2020.104750

47 Almadori G, De Corso E, Visconti G, et al. Impact of internal mammary artery perforator propeller flap in neck resurfacing and fistula closure after salvage larynx cancer surgery: our experience. Head Neck 2019;41:3788-3797. https://doi.org/10.1002/hed.25903

48 Almadori G, Di Cintio G, De Corso E, et al. The usefulness of the IMAP propeller flap for trachea and tracheostome reconstruction after resection of parastomal recurrence of squamous cell carcinoma following salvage total laryngectomy. Eur Arch Otorhinolaryngol 2021;278:499-507. https://doi.org/10.1007/s00405-020-06168-4

49 Giordano L, Di Santo D, Bondi S, et al. The supraclavicular artery island flap (SCAIF) in head and neck reconstruction: an Italian multiinstitutional experience. Acta Otorhinolaryngol Ital 2018;38:497-503. https://doi.org/10.14639/0392-100X-1794

50 Yamazaki H, Ogita M, Himei K, et al. Predictive value of skin invasion in recurrent head and neck cancer patients treated by hypofractionated stereotactic re-irradiation using a cyberknife. Radiat Oncol 2015;10:210. https://doi.org/10.1186/s13014-015-0517-2

51 Jang DW, Teng MS, Ojo B, et al. Palliative surgery for head and neck cancer with extensive skin involvement. Laryngoscope 2013;123:1173-1177. https://doi.org/10.1002/lary.23657

52 Stavrianos SD, Ragbir M, McLean NR, et al. Head and neck skin involvement by non-cutaneous head and neck cancers: free flap reconstruction. Eur J Surg Oncol 2000;26:594-598. https://doi.org/10.1053/ ejso.2000.0953 